\title{
Views from the Frontline: A critical assessment of local risk governance in South Africa
}

\begin{tabular}{|c|c|}
\hline \multicolumn{2}{|l|}{$\begin{array}{l}\text { Authors: } \\
\text { Doret Botha }{ }^{1}\end{array}$} \\
\hline $\begin{array}{l}\text { Affiliations: } \\
{ }^{1} \text { African Centr } \\
\text { Studies, North } \\
\text { University, So }\end{array}$ & $\begin{array}{l}\text { for Disaster } \\
\text {-West } \\
\text { uth Africa }\end{array}$ \\
\hline \multicolumn{2}{|c|}{$\begin{array}{l}\text { Correspondence to: } \\
\text { Doret Botha }\end{array}$} \\
\hline \multicolumn{2}{|c|}{$\begin{array}{l}\text { Email: } \\
\text { doret.botha@nwu.ac.za }\end{array}$} \\
\hline \multicolumn{2}{|c|}{$\begin{array}{l}\text { Postal address: } \\
\text { Private Bag X600, } \\
\text { Potchefstroom 2520, } \\
\text { South Africa }\end{array}$} \\
\hline \multicolumn{2}{|c|}{$\begin{array}{l}\text { Received: } 06 \text { Sept. } 2012 \\
\text { Accepted: } 07 \text { Jan. } 2013 \\
\text { Published: } 28 \text { Feb. } 2013\end{array}$} \\
\hline \multicolumn{2}{|c|}{$\begin{array}{l}\text { How to cite this article: } \\
\text { Botha, D. \& Van Niekerk, } \\
\text { D., 2013, 'Views from } \\
\text { the Frontline: A critical } \\
\text { assessment of local risk } \\
\text { governance in South Africa', } \\
\text { Jàmbá: Journal of Disaster } \\
\text { Risk Studies 5(2), Art. \#82, } \\
10 \text { pages. http://dx.doi. } \\
\text { org/10.4102/jamba.v5i2.82 }\end{array}$} \\
\hline \multicolumn{2}{|c|}{$\begin{array}{l}\text { Note: } \\
\text { 1st Biennial Conference, } \\
\text { Southern African Society for } \\
\text { Disaster Reduction (SASDiR), } \\
09 \text { to } 11 \text { October 2012, } \\
\text { Potchefstroom, South Africa. }\end{array}$} \\
\hline \multicolumn{2}{|c|}{$\begin{array}{l}\text { Copyright: } \\
\text { (C) 2013. The Authors. } \\
\text { Licensee: AOSIS } \\
\text { OpenJournals. This wo } \\
\text { is licensed under the } \\
\text { Creative Commons } \\
\text { Attribution License. }\end{array}$} \\
\hline \multicolumn{2}{|l|}{ Read online: } \\
\hline 口idita & $\begin{array}{l}\text { Scan this QR } \\
\text { code with your } \\
\text { smart phone or } \\
\text { mobile device } \\
\text { to read online. }\end{array}$ \\
\hline
\end{tabular}

In 2005 the United Nations International Strategy for Disaster Reduction introduced the 'Hyogo Framework for Action' (HFA) aimed at mainstreaming disaster risk reduction. Subsequently, the 'Global Network for Disaster Reduction' (GNDR) was formed to support the implementation of the HFA. The GNDR initiated a country-based, international research project called 'Views from the Frontline' (VFL) in order to measure progress at local level in terms of compliance with the HFA. The VFL 2011 project focused on local risk governance, which is critical for effective implementation of policy and provision of resources at grassroots level. This article provides insight into the findings for South Africa. The project made use of quantitative and qualitative data. Quantitative data was gathered by means of a survey and/or questionnaire consisting of 20 questions on 'indicators' which assessed progress toward the goals of the HFA. The surveys also provided for qualitative commentary. The target population for this research consisted of local government officials and community representatives. Based on the quantitative scores for all the different indicators, the research showed that South Africa could still improve significantly in terms of compliance with the HFA. More attention must be given to operationalise the HFA at local level, a culture of safety must be fostered, local actors and communities must be involved directly and consulted, indigenous knowledge must be recognised, and significant capacity development for disaster risk reduction is necessary.

\section{Introduction}

The United Nations International Strategy for Disaster Reduction (UNISDR) established a 10-year programme for improvement in Disaster Risk Reduction (DRR) in 2005 and introduced the 'Hyogo Framework for Action' (HFA) (World Conference for Disaster Reduction 2005). The HFA highlighted five priorities for action, namely:

- governance for disaster risk reduction

- risk assessment, monitoring and warning

- knowledge and education

- underlying risk factors

- disaster preparedness and response.

Despite this intention of the United Nations (UN), many non-governmental organisations (NGOs) were concerned that the high-level policy would not effectively be implemented at the 'frontline' in the millions of communities around the world that are exposed to natural disasters. To this end, the 'Global Network for Disaster Reduction' (GNDR) was formed to support the implementation of the Hyogo Framework for Action (HFA) (GNDR 2010:2).

In 2008, the GNDR initiated an international research project named 'Views from the Frontline' (VFL) in order to measure progress at a local level in terms of compliance with the HFA. The initial phase of the project was a highly effective collaborative effort. It gathered responses from over 7000 respondents in 48 countries. The project highlights the areas where more action is needed, and also builds local level partnerships to mobilise more effective DRR interventions (GNDR 2010:2).

South Africa participated in the first VFL project (2008-2009), as well as the 2010-2011 VFL project. From the findings of the 2008-2009 VFL project it was clear that South Africa could still improve significantly toward compliance with HFA. All five priorities for action were rated below three (out of a possible five). The highest score was achieved for cross-cutting issues (2.51) followed by underlying risk factors (2.4), preparedness and response (2.31), governance (2.27), risk assessment and monitoring (2.04), and knowledge and education (1.88) (Van Riet et al. 2009:35).

The next phase of the programme, 'Views from the Frontline 2011', built on the successes of the initial project, focusing on local risk governance, which is critical to effective implementation of 
policy and provision of resources as it impacts on the ground, where people who are at risk live, eat and work (GNDR 2010:2). Twenty thousand views on local risk governance and 57 case studies were collected in 69 countries (GNDR 2011).

The VFL 2011 specific objectives were:

- To strengthen public accountability for effective HFA implementation by establishing independent local-level policy monitoring and reporting processes.

- To strengthen collaboration between local, national, regional and international levels.

- To increase dialogue and interaction between local authorities, civil society and community stakeholders in order to monitor progress, share information, formulate policy positions, develop partnerships and coalitions and contribute toward multi-stakeholder efforts to implement the HFA on the ground (GNDR 2010:3).

The project outputs at the country and regional level included, amongst others, the following:

- To provide an independent global overview of progress, baseline and evidence aimed at developing effective local governance for implementation of the HFA.

- To improve understanding of the role and importance of local governance in order to support effective implementation of the HFA at the local level.

- To increase research, analytical and advocacy capabilities among project participants.

- To increase public awareness, ownership and demand for building safety and resilience.

- To promote joint advocacy and strategy at the national, regional and international level.

- To increase understanding and trust between the public, civil society and community stakeholders responsible for DRR.

- To promote sharing of practical experience, knowledge and learning.

- To increase political commitment for DRR investments at the local level (GNDR 2010:2).

The objectives of this paper are to provide an overview of DRR in South Africa; to present and discuss the major findings of the Views from the Frontline 2011 project; to provide an assessment of local risk governance in South Africa; and to make recommendations for effective local risk governance in South Africa.

\section{Overview of Disaster Risk Reduction in South Africa}

The subject of disaster risk management (DRM) and disaster risk reduction in South Africa draws its relevance from earlier contributions and previous practices in the disaster management fields, where traditionally the focus has been on preparedness for response. DRR emphasises a new global thinking (since 2005 onwards) in the management of hazards, vulnerability and disaster risk. The Constitution of the Republic of South Africa Act 108 of 1996 (South Africa 1996), places a legal obligation on the government of South Africa to ensure the health (personal and environmental) and safety of its citizens. In terms of subs. 41(1)(b) of the Constitution, all spheres of government are required to 'secure the wellbeing of the people of the Republic'. Subsection 152(1) (d) also requires that local government 'ensure a safe and healthy environment'. It is therefore the duty of government to implement DRM and also to plan for climate change adaptation and mitigation to reduce the vulnerability of people, infrastructure and other national assets to various hazards (also those relating to climatic change) (Bulkeley \& Betsill 2005). The primary responsibility for DRR in South Africa thus rests with government.

South Africa was one of the first African countries to comprehensively legislate DRM (Vermaak \& Van Niekerk 2004). In a process which started in June 1994 (South Africa 1998; South Africa 1999) and culminated in the Disaster Management Act 57 of 2002 (DMA) (South Africa 2003) (under revision in 2013), and the National Disaster Management Policy Framework (NDMF) (South Africa 2005) in 2005, South Africa established itself as a nation at the forefront of covering DRR within its public sector (Pelling \& Holloway 2006). This Act and Policy facilitated a shift in traditional disaster response and management thinking, to that of DRR (Reid 2005; Reid \& Van Niekerk 2008; Van Niekerk 2005, 2006). The decentralisation of responsibilities calls for the three tiers of government (local, provincial and national) in South Africa to incorporate the function of DRR within their hierarchical structure (Van Niekerk 2006), with a particular emphasis on intergovernmental cooperation and integrated development planning.

The DMA places a premium on the decentralisation of DRR activities (Pelling \& Holloway 2006). Such decentralisation should occur across the three spheres of government (local, provincial and national) and within government departments. The main thrust of the DMA and NDMF revolves around the creation of appropriate institutional arrangements for DRR. Each town, city and rural area in South Africa has a different risk profile and therefore faces a variety of different threats of different magnitude. To implement the DMA and NDMF, the responsibility at local government level for DRR falls on metropolitan and district municipalities ${ }^{1}$, although practice has shown that implementation happens within local municipality with the districts playing more of a coordination role. Many of these local municipalities have a shared disaster risk profile which spans geographical boundaries.

\section{The disaster risk profile of South Africa}

South Africa is generally not regarded as a country at high risk for disasters; however, the country is beset by many risks and hazards, both natural and human-made. These risks and hazards include, amongst others: veld-/wildfires,

1.Within the South African administrative structure for local government one finds three types of municipalities: local, district and metropolitan. A district normally three types of municipalities: local, district and metropolitan. A district normally
consists of a number (4-7) of local municipalities whereas a metropolitan municipality does not have any local municipalities under its jurisdiction. 
severe weather events, drought, floods, extreme hailstorms, winds, structural fires, road accidents, sinkholes, dolomitic areas, earthquakes due to mining activity, mass events in the outbreak of biological diseases such as meningitis and cholera, and epidemics such as HIV, tuberculosis and malaria (UNDP 2011).

Furthermore, the majority of South Africa's population lives in vulnerable conditions due to high levels of poverty, low standards of living, high levels of unemployment, lack of access to resources, lack of education, unequal patterns of asset ownership and distribution, environmental degradation and slow economic growth (UNDP 2011). Risk implication and vulnerabilities are also higher in areas characterised by increasingly high development pressure on the natural environment and by high socio-economic vulnerability (South Africa 2010:15). According to Botha et al. (2011:20), the impact of poverty is a pivotal factor in the progression of vulnerability to hazards. Van Niekerk et al. (2002:63-64) state that this is of particular relevance in the South African scenario, with the huge legacy left by the apartheid government of desperately impoverished and disadvantaged communities who are, as a result, extremely vulnerable to disasters. The authors further argue that it is within these local communities that the smaller but much more frequent hazards occur, and where the costs in terms of loss of lives and property and the financial burden are borne painfully. It is within the context above that the VFL 2011 project was initiated.

\section{Research methodology}

The project made use of both quantitative and qualitative data. Quantitative data were gathered by means of a faceto-face survey consisting of 20 questions on 'indicators' which assess progress towards the goals of the HFA. The responses they provide produce an assessment of people's perception of progress. The surveys also provided for qualitative commentary where respondents could elaborate on a significant point in relation to a specific question. Additionally, qualitative data were gathered by means of case studies that illustrate successes, challenges and lessons learnt toward the goals of the HFA. Data derived from the case studies will not be presented in this paper but are available on the GNDR website: www.globalnetwork-dr.org.

The following ranking for scores was used:

1. No.

2. To a very limited extent.

3. Some activity but significant scope for improvement.

4. Yes, but with some limitations in capacities and resources.

5. Yes, with satisfactory, sustainable and effective measures in place.

6. Don't know.

The benchmark (ideal) in terms of responses for every statement would be ' 5 ' which indicates that compliance toward the specific statement is satisfactory. Ratings below ' 3 ' will be regarded as 'low' and indicate that compliance toward the specific statement is non-existent or very limited.
A rating of ' 3 ' indicates that there is some activity toward compliance with the statement, but with significant scope for improvement. Statements that obtain a rating of ' 4 ' indicate compliance toward the statement but with limitations in capacity and resources.

The target population for this research was made up of local government officials and community representatives. Local government officials included both the lowest tier of local representatives of national government departments and ministries, such as schoolteachers and public health officials, as well as local administrative authorities, such as municipal bodies. Community representatives included selected members that live in various communities at risk, some in urban and others in rural areas. Selected communities included representatives of gender, age, ethnicity as well as vulnerable and traditionally marginalised groups such as women, children, the elderly and the disabled (GNDR 2010:4).

A total number of 355 surveys were completed for the South Africa region. Research was conducted in all nine provinces of South Africa (see Figure 1). The main at-risk communities were selected by contacting provincial and/or district disaster management officials to identify the most atrisk communities in the different provinces. The respondent breakdown per province was established according to the estimated population of a specific province.

The aim of the research project was to interview at least 20 local government officials and community members in each research setting. The GNDR suggested a mix of approximately five local government officials (which constituted 25\%) and 15 community members (which constituted 75\%) in each research setting. The suggested numbers are in line with the numbers of respondents interviewed as reflected in Figure 2 below. Nineteen per cent (69) local government officials, 76\% (268) community members, $2 \%$ (8) civil society participants and $3 \%(10)$ others were interviewed.

\section{Research findings}

According to the GNDR (2011:6), 'effective local risk governance happens when a capable, accountable and

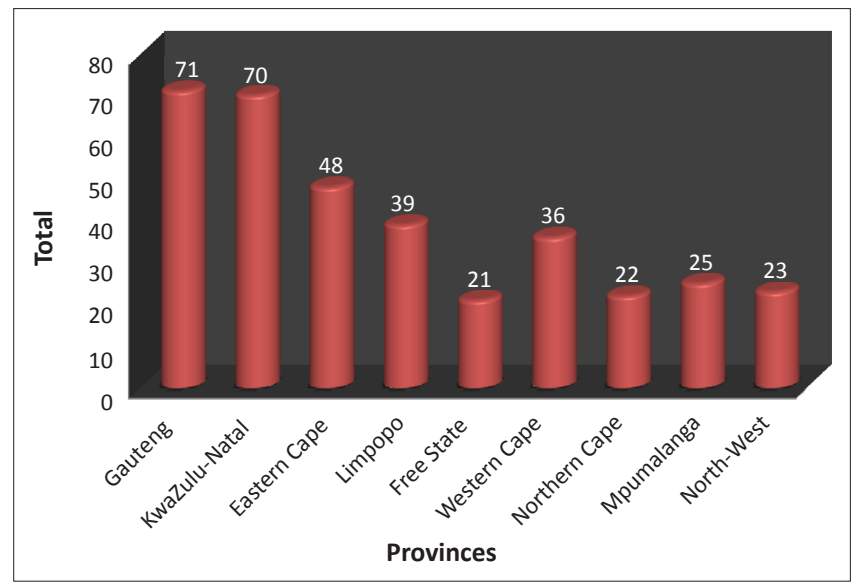

Source: Created by authors for paper

FIGURE 1: Location of respondents according to the nine provinces of South Africa. 
responsive local government works together with civil society, the private sector and at-risk communities'. Members of the GNDR identified three key aspects of local risk governance, namely 'inclusion and participation', 'local capacity and capability' and 'accountability and transparency'. Indicators for each of these aspects were identified. The findings will be discussed in line with these three key aspects and the associated indicators.

\section{Indicators: Inclusion and participation}

Inclusive governance involves shared decision-making power between local authorities and local stakeholders, such as different grassroots organisations, civil society actors and volunteer groups, as well as the vulnerable and marginalised groups that include children, adults and the elderly. 'Vulnerable people' refers to people who are especially susceptible to the effects of extreme hazards, as a result of physical, social, economic and political factors. They and others can also be marginalised by their society due to their ethnicity, age, sex, class, political affiliations or religion. Inclusive decision-making is thus important in order to create a sense of ownership that may eventually lead to more appropriate, cost-effective and sustainable interventions regarding disaster prevention (GNDR 2010).

The following five indicators were identified to seek views on 'inclusion and participation':

- There is participation by all, especially vulnerable and marginalised groups, in disaster prevention decisionmaking and implementation.

- There is gender equality with women and men participating equally in decision-making and implementation.

- The specific needs of children and young people are taken into account.

- Local volunteers take part in disaster prevention measures.

- Partnerships exist between local government, community, private sector, civil society, academia and others (GNDR 2011:6).

The average score for participation across all respondent types was 1.9 and is an indication that an inclusive decisionmaking approach is not followed by government. Qualitative data revealed that community respondents felt excluded from decision-making processes. They argued that the government follows a top-down process with local government officials telling community members what to do, but not asking community members what they think should be done.

The indicator for gender had an average mean score of 2.6. The aim of this indicator is to verify whether government follows a gender sensitive approach, that is, the full and equal involvement of men and women in disaster prevention decision-making and implementation. Qualitative data revealed that community respondents are of the opinion that men seem to be more involved in disaster prevention than women. Furthermore, they indicated that the involvement

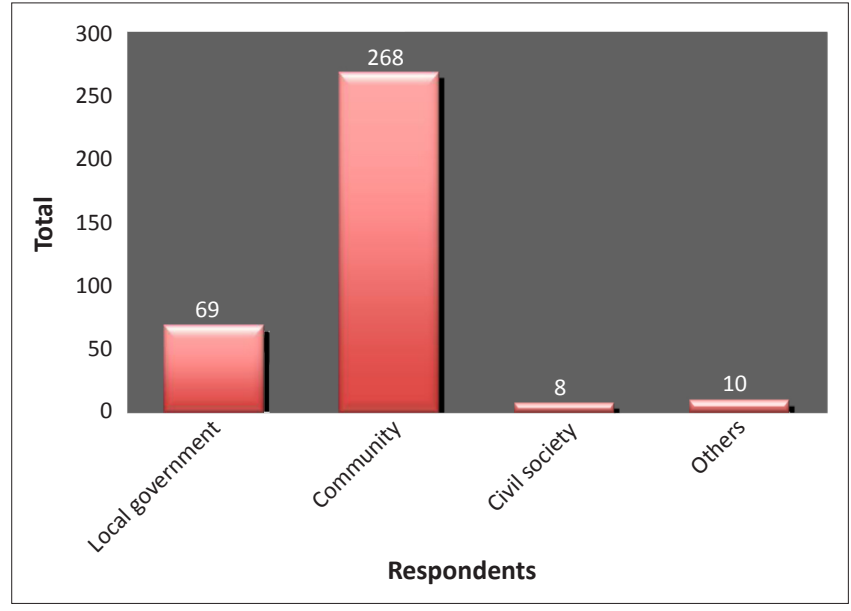

Source: Created by authors for paper

FIGURE 2: Respondents' informant group and occupation.

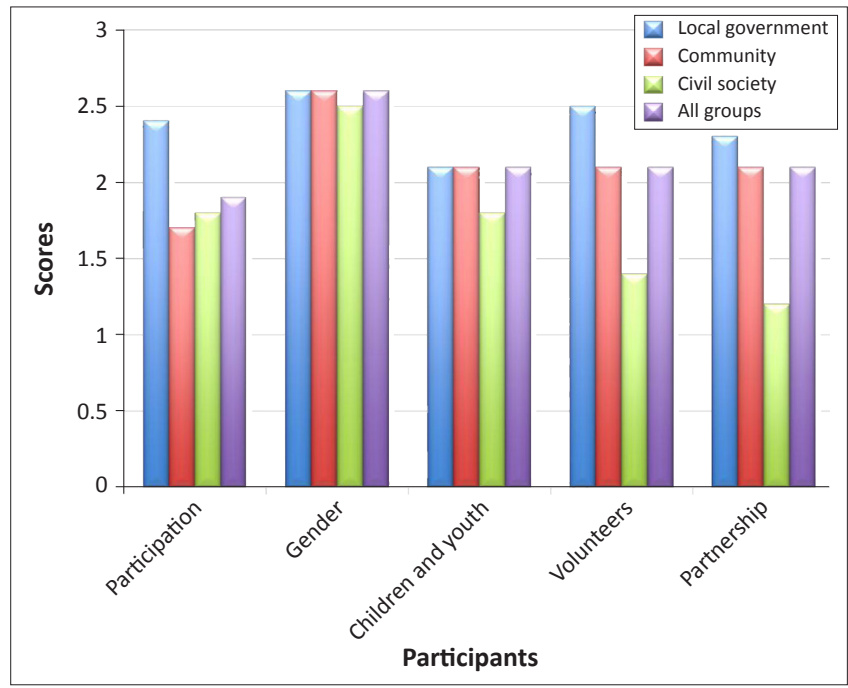

Source: Created by authors for paper

FIGURE 3: Overall mean scores for indicators on inclusion and participation.

of women in disaster prevention decision-making and implementation should help to improve their situation.

The average score for children and youth across all respondent types was 2.1. Community respondents indicated that the needs of the youth are not being catered for, especially with regard to healthy living, environment and education on HIV and other epidemics. This low score stresses the importance for governance to take into account the specific needs of children and young people with regard to disaster practices. Children are seen as effective agents of change at community level, and therefore local government has to involve them in disaster practices.

The indicator on volunteers assesses whether government recognises the role of voluntary action as contributing toward capacity-building in DRR and whether government engages specific mechanisms to ensure the active participation of volunteers and build on the spirit of volunteerism (GNDR 2010). The average score for volunteers across all respondent types was 2.1. Qualitative data indicated a great need for volunteers working on disaster prevention 
and DRR in communities. Data also revealed that in cases where volunteers exist, they do not seem to be active in all the communities, and that community members have to rely on help from neighbours in cases when disasters happen. Other respondents mentioned that volunteers that do work in the communities are not experienced and also need more expertise. These findings are in line with research conducted by Botha et al. (2011:38) which found that although the majority of district and local municipalities indicate that they do have volunteer structures in place, these structures are functioning at a very low level. The establishment of well-functioning volunteer units is an important mechanism to ensure cooperation between local government and communities in DRR.

Inclusive governance requires a holistic approach and thus the involvement of different stakeholders, the community, the private sector, civil society, academia and others. The average score for partnership across all respondent types was 2.1 and is an indication that partnership does exist to a limited extent, but with significant scope for improvement.

\section{Indicators: Local capacity and capability}

Effective local risk governance depends on local capacity and capability. Therefore leaders, state authorities, private and public organisations all play a role in ensuring local capacity and capability. These can be acquired through formal education and training and also through 'learning by doing' and sharing of experiences. It also involves understanding and maximising local (indigenous) knowledge and, where necessary, combining this with outside specialist expertise (GNDR 2011:7).

The following nine indicators were established to verify local government levels of local capacity and capability in local risk governance:

- Disaster prevention policies are in place to protect vulnerable people (elderly, ethnic minorities, children and youth, disabled, migrants) from disasters, and these policies are regularly reviewed.

- Local disaster prevention practices take into account local (indigenous) knowledge, skills and resources.

- There is a local plan of action to turn disaster prevention policies into practice.

- Local government has an adequate budget for disaster prevention.

- Local government officials have clear roles and responsibilities in carrying out disaster prevention.

- Disaster prevention training is provided for government officials, the community and civil society leaders.

- There is sufficient expertise in local government to carry out disaster prevention.

- Traditional and scientific knowledge informs local action planning.

- Disaster prevention activities are coordinated between local government and other government officials and ministries.

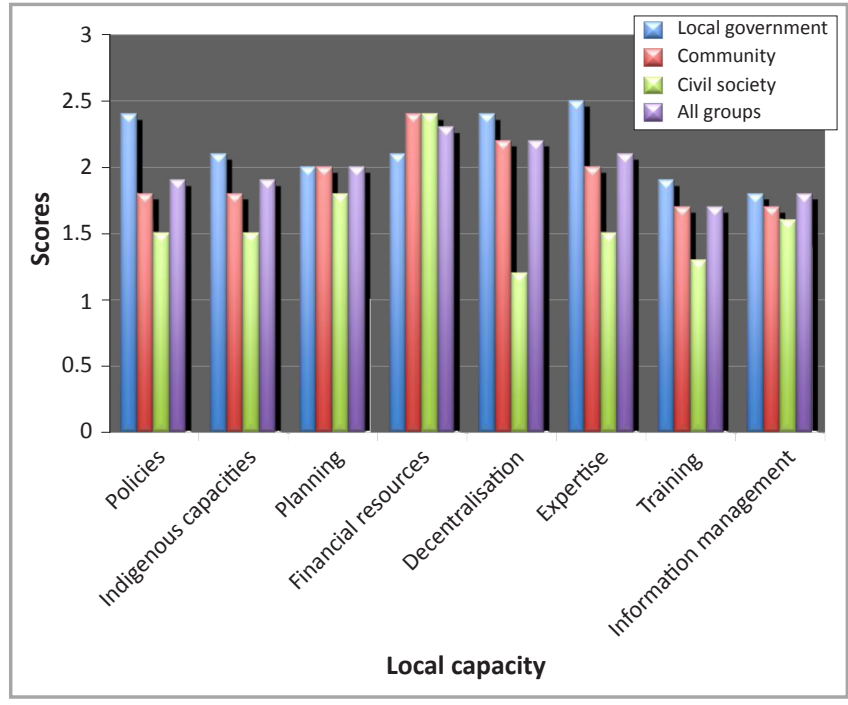

Source: Created by authors for paper

FIGURE 4: Overall mean scores for indicators on local capacity and capability.

The average score for policies across all respondent types was a low 1.9. According to qualitative data, community respondents felt that disaster prevention policies need to be implemented with more 'eagerness' on the part of local government. Respondents indicated that these policies must be decentralised to local municipality level and not only to district level. They also specify that these policies have to be work-shopped with communities.

In order for effective DRR to take place it is necessary for local government to take an integral approach. It thus requires local government to value and assess at-risk people's own capacities and coping strategies as integral elements for effective risk reduction practices. This also implies, amongst others, that government has to gather information on traditional practices, local customs and indigenous knowledge when developing risk profiles and action plans (GNDR 2010). The average score for indigenous capacities across all respondent types was 1.9. Qualitative data revealed that community members felt that government officials make no effort to attract community members to share their indigenous knowledge relating to disaster prevention with them. Respondents argued that government only focuses on a scientific approach to disaster reduction and that indigenous methods are not considered. They said government prefers to make use of 'white solutions' to address disaster risk problems. Once again, community members claimed that government follows a 'top-down' approach and does not take into account local (indigenous) knowledge, skills and resources with regard to disaster prevention practices. The importance of indigenous knowledge is reinforced by the Disaster Management Act 57 of 2002, s. 17(2)(g) (South Africa 2003:20), which states that the electronic database developed by the National Disaster Management Centre must contain extensive information concerning disasters that occur or may occur in southern Africa and disaster management issues, including information on indigenous knowledge relating to disaster management. 
The indicator on planning assesses whether action plans are in place at local level within the relevant line-ministries and local administrative offices and whether planning is undertaken with the active participation of at-risk people. The average mean score for planning across all respondent types was 2. Qualitative data revealed that community members had suffered big losses (e.g. livestock, plantations, grazing and housing) in the past due to slow disaster management actions from government. Some respondents indicated that there is no disaster preparedness at all from the government's side. Community members also mentioned that there does not seem to be any form of cooperation amongst the government departments regarding disaster prevention. Community members complained that they do not get any information regarding the risks that they are living with. Furthermore, respondents felt strongly that disaster reduction policies and plans have to be implemented and carried out. The abovementioned data are a clear indication that local government struggles to turn disaster prevention policies into practice.

The aim of the indicator on financial resources is to determine whether resources are allocated in local administrative budgets to support the implementation of DRR measures in all the relevant sectors of government ministries and departments. Furthermore, the aim is to establish whether funding targets exist for local level implementation and whether incentives and mechanisms are in place to channel funding directly to local initiatives, at-risk communities and local authorities. The average score for financial resources across all respondent types was 2.3. According to the qualitative data, some community respondents indicated that they think there are funds available for disaster prevention measures but that funds are not applied correctly and effectively. Others indicated that they are not sure whether the budget allocated for disaster prevention is adequate, because government officials always say 'that they don't have enough money'. Some community members also indicated that the government couldn't do enough for the victims of a disaster due to a lack of funding. These findings correlate with research conducted by Botha et al. (2011:45). The findings revealed that although local government respondents often have a budget available for carrying out DRM activities, these are usually not adequate for their needs, or for the successful and sustained implementation of projects. Furthermore, budgets allocated generally fail to cover costs and expenditure related to training, capacitybuilding, public awareness, workshops, risk reduction project implementation and the adequate provision of emergency relief supplies.

The average score for decentralisation across all respondent types was 2.2. The aim of the indicator is to determine whether the roles, responsibilities and authority levels for organisations and officials are clearly defined and allocated within the relevant line-ministries and local administrative offices. In South Africa, the function of disaster management and/or prevention is often viewed as the responsibility of the National Disaster Management Centre. It seems that the various departments in local municipalities do not understand their respective roles and/or responsibilities in terms of disaster management (Botha et al. 2011:67).
Effective DRM necessitates clearly defined and allocated roles, responsibilities and authority levels for organisations and officials within the relevant line-ministries and local administrative offices. Furthermore, the establishment of links and exchanges between local and national government level, as well as between legislators and implementing authorities, is also fundamental.

For effective local risk governance to take place it is important that local government officials targeted with disaster prevention have sufficient expertise, including technical, management and planning skills, to plan and implement DRR actions. The average score for expertise across all respondent types was 2.1. It is clear from the low score that respondents do not think that local government has adequate expertise to carry out disaster prevention. This correlates with the findings of Botha et al. (2011:41) that indicated that government officials at provincial level also felt that staff at local government level are not adequately trained. For effective DRR and DRM to take place well-trained staff are needed. It is therefore of the utmost importance that capacity-building and training regarding DRM and DRR should be promoted, especially at local government level.

Local government must be committed to building the skills and competencies of local government officials as well as community leaders in community-based DRM. Furthermore, local government must provide the necessary education, learning and training support to develop leadership and professional competencies in order to formulate, manage and review DRR policies, strategies, programmes and projects, including technical skills and expertise associated with the required duties in specific sectors and approaches (GNDR 2010). The average score for training across all respondent types was a low 1.7 and stressed the current lack of training that exists in the country. This is not limited to government officials but also includes training given to community and civil society leaders regarding disaster prevention issues. To increase involvement in DRM it is important to keep all key participant groups, that is, government officials and civil society leaders as well as community members, informed about DRM issues.

From the face-to-face surveys it was detected that community respondents believe that adequate training on disaster prevention will definitely empower them to prepare for disasters and even prevent disasters from happening. Coping capacity will also be increased in areas affected by previous disasters. Community members stated that in instances where training is provided, it is targeted at local government officials. Community respondents suggested that schools in communities should be involved in training projects. These respondents also suggested that training must be specific to the needs of the community, with a strong focus on gender, youth and disability. Some community members also raised concerns about climate change and the risk of rising sea levels. They suggested that government focus training on informing and/or educating coastal communities on issues regarding climate change and the risk of rising sea levels, as well as relevant coping mechanisms. 
The aim of the indicator on information management is to determine whether the gathering of information takes into account the culture, livelihoods and population structure of vulnerable groups, and, furthermore, to find out if local indigenous knowledge is linked with scientific knowledge, for example, climate change scenarios and forecasts. It is also important that learning exchanges take place in order to share ideas and knowledge between local leaders, change agents and decision-makers (GNDR 2010). The average score for information management across all respondent types was 1.8. As already mentioned, respondents indicated that government only focuses on a scientific approach to disaster reduction and that indigenous methods are not considered. A greater convergence of traditional and scientific knowledge is needed to ensure that communities are not only planned better, but are also safer.

The average score for governmental coordination across all respondent types was 2.3. Community members indicated that there does not seem to be any form of cooperation between the government departments with regard to disaster prevention. Research conducted by Botha et al. (2011:99) also reflected the lack of coordination that currently exists between local government and other government departments. Van Niekerk (in Botha et al., 2011:99) states that in order to comply with the requirements of the Disaster Management Act it is crucial for different government departments to follow an integrated approach with regard to DRM. The author continues by emphasising that the absence of political will and clear policy guidelines to ensure that DRR measures are implemented, will only lead to further risk-creating behaviour and unsustainable development practices.

\section{Indicators: Accountability and transparency}

Accountability and transparency include both public accountability and accountability and transparency on the side of governments and institutions. The latter involves the establishment of transparent baselines, targets, budgets, timelines with clear roles and responsibilities and a measurement process. Community participation and awareness in these aspects will also enhance accountability (GNDR 2011:8).

The following six indicators have been identified to assess levels of accountability and transparency in local risk governance:

- A reference point or baseline has been established from which to measure progress in implementing disaster prevention policies.

- There is regular monitoring and reporting on progress on disaster prevention.

- Communities and civil society are involved with local government in monitoring disaster prevention.

- There is a way for vulnerable people to make complaints and to get a response when there is a lack of progress in disaster prevention.

- Information gathering takes place regularly in order to collect, review and map disaster risks and climate change.
- Updated and easily-understood information about risks and prevention measures is regularly provided to vulnerable people.

All indicators on accountability and transparency score extremely low and require significant improvement. The average score for baselines across all respondent types was 1.8. The baseline indicator assesses whether baselines have been established and time-bound benchmarks and performance targets have been set across relevant ministries and sectors in an attempt to guide actions and drive progress. Furthermore, the indicator assesses whether targets are linked with clear designation of institutional and individual responsibilities to ensure strong political ownership and commitment to the DRR agenda (GNDR 2010). This low score once again stress the need for the establishment of baselines to measure progress in implementing disaster prevention policies.

The aim of the monitoring indicator is to verify whether systematic, simple and timely monitoring systems are in place to measure DRR commitments and progress. The average score for monitoring across all respondent types was 1.8. Monitoring processes must be participatory in nature, utilising qualitative as well as quantitative approaches (GNDR 2010). Therefore, the participatory monitoring indicator assesses whether local government officials, grassroots organisations, affected people and their representatives are fully involved in the monitoring process of disaster prevention. It is important that the information on the progress made be publically available, accessible and communicated to the informant groups. Furthermore, community monitors must be representative of all high-risk groups, with an emphasis on the marginalised. The average score for participatory monitoring across all respondent types was 1.9. These low scores are a clear indication that communities and civil society organisations are not adequately involved in the monitoring of disaster prevention and once again, stress the need for local government to be aware of, and take note of, this fact.

The average score for complaints procedures across all respondent types was 2.4. The aim of the indicator is to

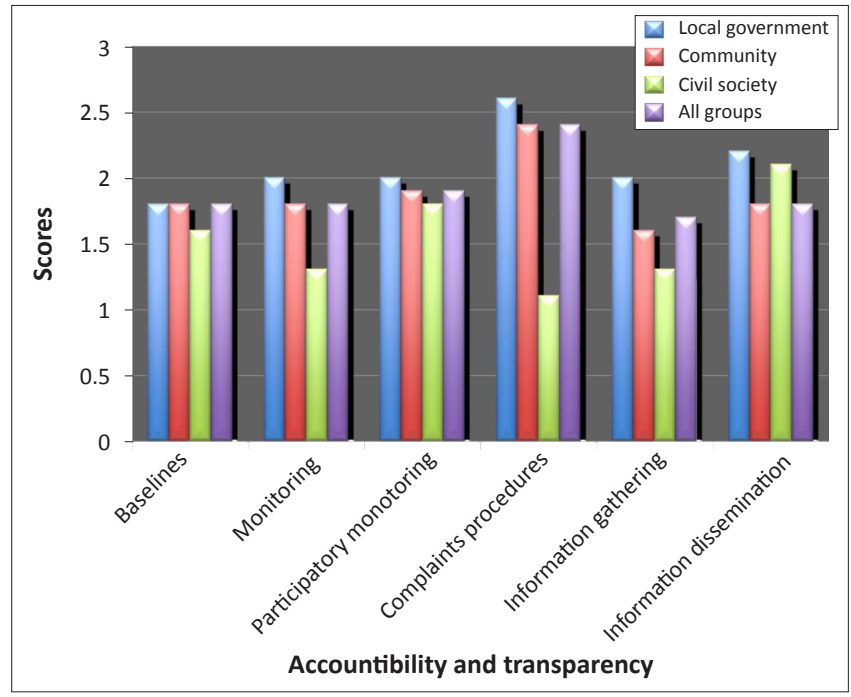

Source: Created by authors for paper

FIGURE 5: Overall mean scores for indicators on accountability and transparency. 
determine whether local government has established, and implements, complaints-handling procedures that are accessible and safe for affected people to complain and seek redress where state authorities do not meet obligations on agreed DRR objectives, targets and standards (GNDR 2010). Qualitative data revealed a need for effective complaintshandling procedures in communities. Community members also indicated that they would like to be kept informed about new findings around the area in which they live in order to be able to cope during times of hardship. They further put forward that they would like to have a suggestion box set up somewhere in the community where complaints can be lodged. It is thus important for local government to establish and implement an effective user-friendly complaintshandling procedure of which communities are fully aware.

The information-gathering indicator assesses whether local government regularly carries out participatory assessments, gathers data and analyses information on climate variables, hazards, local capacities (state and non-state) and vulnerabilities. The average score for information-gathering across all respondent types was 1.7. This overall extremely low score indicates a definite lack on government's part to provide and map information on disaster risks. This needs to be done in order to comply with the National Disaster Management Framework(NDMF), Key Performance Area (KPA) 1 that states that regular disaster risk assessments and monitoring must be carried out by organs of state within all spheres and tiers of government (Van Niekerk 2006:173). These assessments also form the foundation for developing strategies and programme interventions to reduce risk (GNDR 2010).

The average score for information dissemination across all respondent types was 1.8. The indicator seeks to determine whether the affected people are kept informed on a regular basis about the responsibilities, objectives, programmes, budgets and coordination role of local government (GNDR 2010).
The information disseminated must also be presented in such a way that it can be easily understood. Therefore, it must be presented in appropriate languages, formats and media that are accessible and comprehensible to local people and specified stakeholders. From the face-to-face interviews it became clear that community leaders are the best informed regarding DRM and DRR. However, the opposite is true of the community members. In general they complained of not getting any information regarding the risks they are exposed to and the ways they should practise risk reduction. They also claimed that they seldom see local government officials entrusted with the function of disaster management. As mentioned before, some of the community members would like to see pamphlets distributed within the community addressing DRR issues. They also want to be kept informed on a continual basis of new developments and information regarding disaster risks and DRM. This could empower them to make informed choices concerning their living arrangements.

\section{Discussion}

The average score for local risk governance, in terms of all the different indicators, is 2.07. This score is less than the score obtained in the VFL 2009 and 2010 research project. The average score for governance was 2.3. It is thus clear that no improvement has been made in governance relating to DRR and thus compliance with the HFA. The average scores for local risk governance according to the different target groups for the 2010 and 2011 VFL project were as follows:

- local government -2.24

- community - 2.02

- civil society -1.6 .

It is clear from the numbers above that local government rate themselves higher in terms of the different indicators; however, the score is not much higher than the score given by community members (see Figure 6). The poor score given

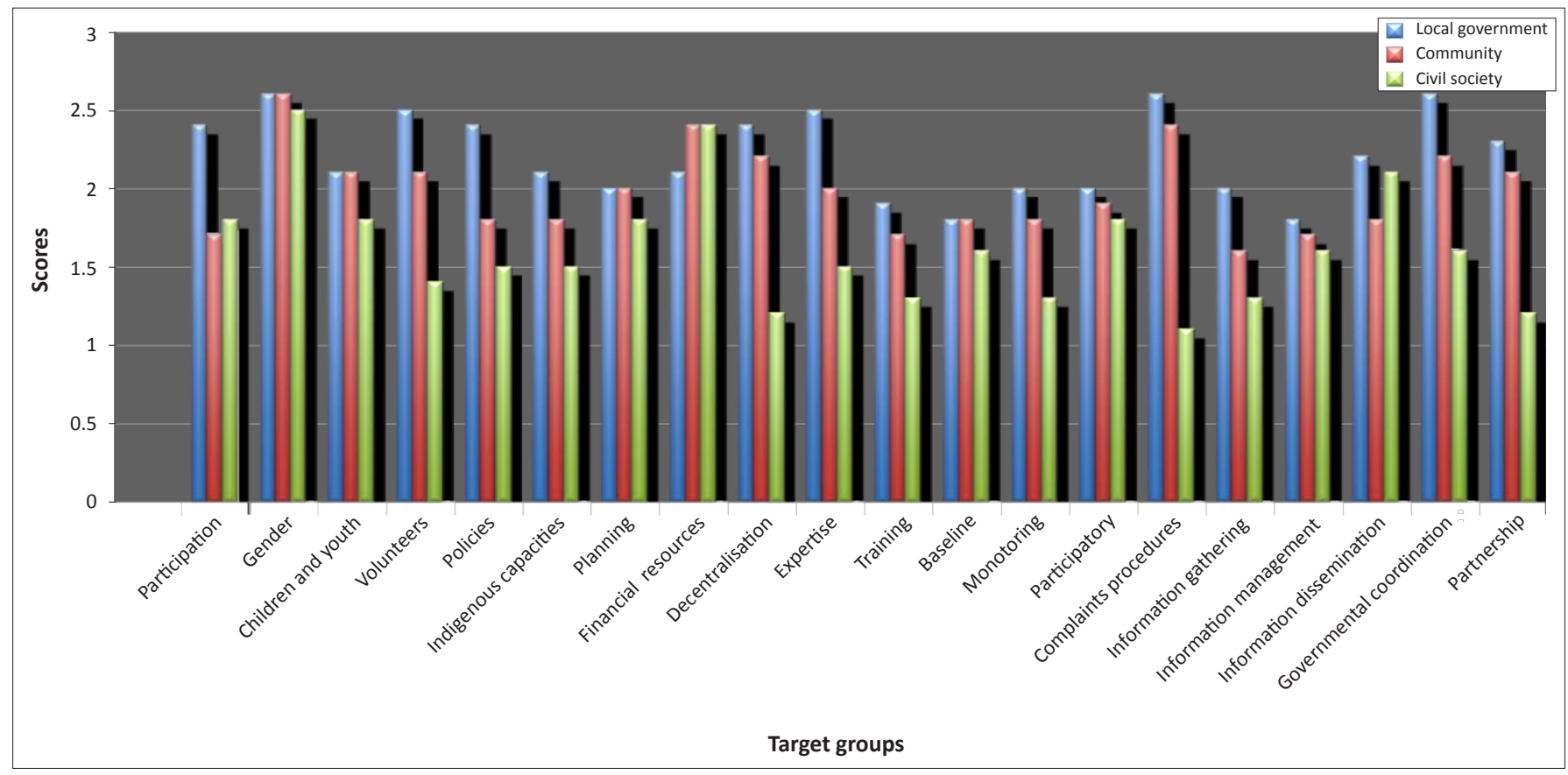

Source: Created by authors for paper

FIGURE 6: Mean scores for local risk governance according to the different target groups. 


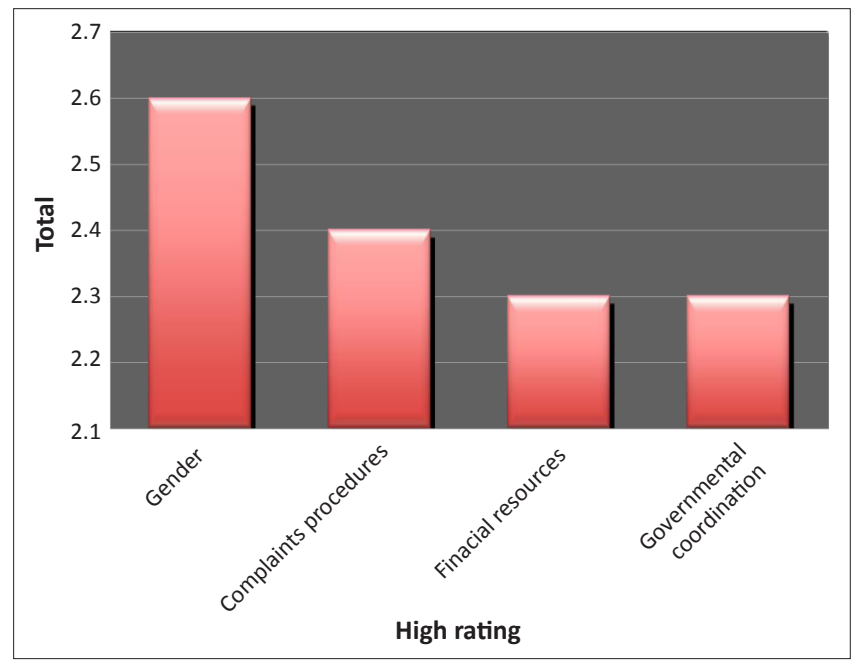

Source: Created by authors for paper

FIGURE 7: Highest scores for local risk governance.

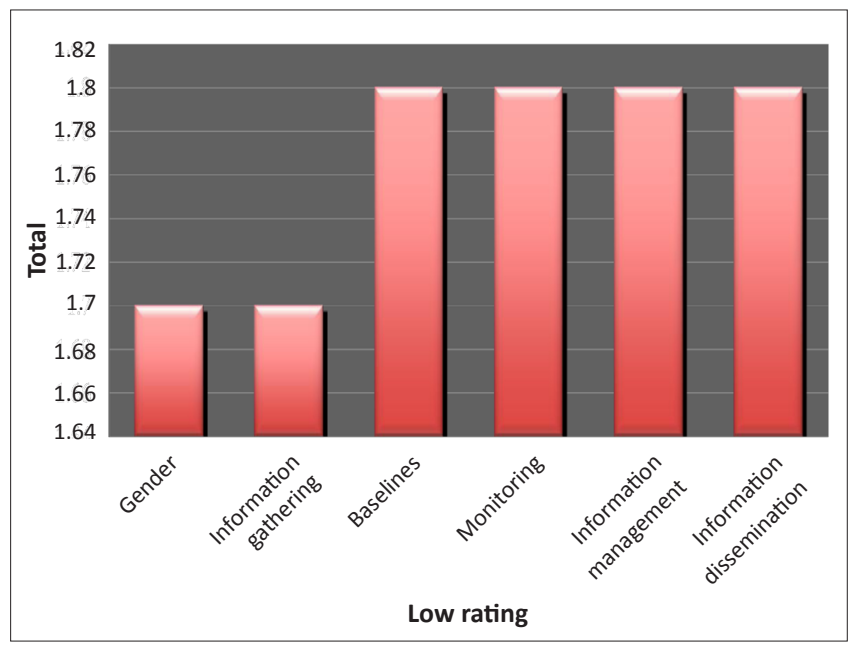

Source: Created by authors for paper

FIGURE 8: Lowest scores for local risk governance.

by civil society respondents is alarming. They rate local risk governance in South Africa at 1.6.

Based on the quantitative scores for all the different indicators, it seems that in terms of local risk governance, South Africa could still improve significantly. All the different indicators were rated below 3, with only one indicator obtaining a score of 2.6. The highest scores were obtained for gender (2.6), followed by complaints procedures (2.4), and financial resources and governmental coordination (2.3). The lowest scores were obtained for training and information gathering (1.7), followed by baselines, monitoring, information management and information dissemination (1.8).

Overall, these scores mentioned above give a clear indication of the poor status of local risk governance in South Africa. These findings are in line with research conducted by Botha et al. (2011:101) on the status of DRM in municipalities in South Africa, that indicated that the majority of municipalities in South Africa do not take DRR seriously. A general lack of skills, competencies, equipment, funding allocation and political will are trademarks of local governance with regard to disaster prevention in South Africa. This is also reinforced by qualitative commentary as discussed in the Research Findings section.

\section{Conclusion and recommendations}

The purpose of this paper was to provide a critical assessment of local risk governance in South Africa. From the findings it is clear that South Africa could still improve significantly in this regard. In conclusion, the following suggestions and recommendations can be made to strengthen local risk governance in South Africa.

Local government should aim to involve all people, especially vulnerable and marginalised groups in disaster risk reduction and/or prevention. They can do that in the following ways:

- Arrange regular meetings in the community where community members can be informed and also contribute to disaster-related issues such as policies, disaster risk assessments, disaster prevention, disaster response, et cetera.

- Local government must aim to involve both women and men as well as vulnerable and marginalised groups, such as the elderly, disabled, and migrants, to participate in community meetings regarding disaster risk issues.

- Local government should aim not to follow a 'topdown' process by telling community members what to do during meetings but to involve them by encouraging them to give input with regard to disaster-related issues.

- Regular training and awareness programmes must be created to sensitise community members on disasterrelated issues, such as risk awareness, risk reduction, preparedness and response. The visual, print and radio media should be involved in efforts to increase community awareness.

- Training programmes focusing on the youth can be implemented in school programmes to create awareness of disaster-related issues, such as disaster prevention and response, healthy living, HIV and other epidemics.

- Local government must give community members the opportunity to share and include their local (indigenous) knowledge, practices, skills and resources in disaster prevention practices.

- Policies regarding disaster prevention need to be implemented with more 'eagerness' on the part of local government and must be decentralised to local municipality level and not only to district level. The content of these policies must be work-shopped with the communities.

- Local government must implement an efficient complaints procedure which provides for the lodging of complaints as well as feedback.

- Local government must give feedback to the community on a regular basis regarding new risks and/or hazards, contingency plans, policies, et cetera.

Furthermore, local government should aim to provide the necessary structures and support in the application of 
disaster risk reduction and/or prevention. It is therefore recommended that local government:

- Provide regular training programmes for government officials to empower them to carry out their disasterrelated tasks and duties.

- Establish mechanisms to promote and support research on disaster-related issues at national and local level. Local government must collaborate with institutions of higher learning and other experts to identify appropriate research mechanisms.

- Carry out regular disaster risk assessment, regarding natural or other hazards and conditions of vulnerability, at local level to compile a risk profile and plan an effective risk reduction programme. Local government should engage with institutions of research as partners to assist them with the process.

- Ensure that well-trained and well-functioning volunteer units are established to assist communities in terms of disaster risk issues.

- Provide adequate funding and the efficient management thereof, which remains one of the critical issues concerning successful disaster risk reduction and/or management to be carried out. As clearly indicated in the research, communities complained about an increase in disaster losses due to inadequate funding and the slow disaster management that took place.

- Promote the political will to be committed to DRR/DRM in the sphere of government.

\section{Acknowledgments}

The authors would like to acknowledge the funding received from USAID under grant no: AID-OFDA-G-11-00077 for the field research.

\section{Competing interests}

The authors declare that they have no financial or personal relationship(s) which may have inappropriately influenced them in writing this paper.

\section{Authors' contributions}

D.v.N. (North West University) was the project leader. D.B. (North West University) was responsible for data analysis and write-up.

\section{References}

Botha, D., Van Niekerk, D., Wentink, G., Tshona, T., Maartens, Y., Forbes, K., Annandale, E., Coetzee, C. \& Raju, E., 2011, Disaster risk management status assessment at municipalities in South Africa, South African Local Government Association (SALGA), Pretoria.

Bulkeley, H. \& Betsill, M.M., 2005, Cities and climate change: urban sustainability and global environmental governance, Routledge, Oxon.

GNDR (Global Network for Disaster Reduction), 2010, 'Views from the frontline 2011: Quick start guide for NCOs and POs', viewed 01 October 2012, from http://www. globalnetwork-dr.org/document-library-.html (password protected)

GNDR, 2011, 'If we do not join hands: Views from the Frontline: Local reports of progression implementing the Hyogo Framework for Action, with strategic recommendations for more effective implementation', viewed 01 October 2012, from http://www.preventionweb.net/english/professional/publications/v. php?id=19857

Pelling, M. \& Holloway, A., 2006, Legislation for mainstreaming disaster risk reduction, Tearfund, Teddington.

Reid, P.M., 2005, 'A model for an incident management system for South Africa', Masters dissertation, North West University, Potchefstroom.

Reid, P.M. \& Van Niekerk, D., 2008, 'A model for a multi-agency response management system (MARMS) for South Africa', viewed 01 October 2012, from http://dx.doi. org/10.1108/09653560810872541

South Africa, 1996, The Constitution of the Republic of South Africa Act 108 of 1996, Government Printer, Pretoria.

South Africa, 1998, Green Paper on Disaster Management, Government Printer, Pretoria.

South Africa, 1999, White Paper on Disaster Management, Government Printer, Pretoria.

South Africa, 2000, Municipal Systems Act 32 of 2000, Government Printer, Pretoria.

South Africa, 2003, Disaster Management Act 57 of 2002, Government Printer, Pretoria.

South Africa, 2005, National Disaster Management Policy Framework, Government Printer, Pretoria.

South Africa, 2010, 'South African risk and vulnerability atlas', Department of Science \& Technology, viewed 03 June 2011, from www.rvatlas.org

South African National Disaster Management Centre, n.d., viewed 22 September 2011, from www.ndmc.gov.za

UNDP (United Nations Development Programme), 2011, 'South Africa: building capacity of the national disaster management authority', viewed 22 September 2011, from www.undp.org/cpr/disred/documents/publications/.../africa/sa.pdf

Van Niekerk, D., 2005, 'A comprehensive framework for multi-sphere disaster risk reduction in South Africa', doctoral thesis, North West University, Potchefstroom.

Van Niekerk, D., 2006, 'Disaster risk management in South Africa: the function and the activity - towards an integrated approach', Politeia 25(2), 96-116.

Van Niekerk, D., Reid, P. \& Mokonyama, T., 2002, 'Disasters: A Theoretical Perspective', study guide for the Certificate Course in Disaster Studies, African Centre for Disaster Studies, North-West University, Potchefstroom.

Van Riet, G., Maartens, Y., Coetzee, C. \& Thabang, T., 2009, 'Global network for disaster reduction, Views from the Frontline project 2008-2009: progress with the implementation of the Hyogo Framework for Action 2005-2015. Draft country report for South Africa', unpublished, North West University, Potchefstroom.

Vermaak, J. \& Van Niekerk, D., 2004, 'Disaster risk reduction initiatives in South Africa', Development Southern Africa 21(3), 555-574.

World Conference on Disaster Reduction, 2005, 'Hyogo Framework for Action: 20052015: Building the Resilience of Nations and Communities to Disasters', viewed 22 September 2011, from http://www.unisdr.org/2005/wcdr/intergover/officialdoc/L-docs/Hyogo-framework-for-action-english.pdf 